\title{
Monitoring the genomic stability of in vitro cultured rat bone-marrow-derived mesenchymal stem cells
}

\author{
Dana Foudah • Serena Redaelli • Elisabetta Donzelli • Angela Bentivegna • \\ Mariarosaria Miloso • Leda Dalprà • Giovanni Tredici
}

Received: 7 July 2009/Revised: 29 September 2009 / Accepted: 7 October 2009 / Published online: 2 December 2009

(C) Springer Science+Business Media B.V. 2009

\begin{abstract}
Bone-marrow-derived mesenchymal stem cells (MSCs) are multipotent cells capable of selfrenewal and differentiation into multiple cell types. Accumulating preclinical and clinical evidence indicates that MSCs are good candidates to use as cell therapy in many degenerative diseases. For MSC clinical applications, an adequate number of cells are necessary so an extensive expansion is required. However, spontaneous immortalization and malignant transformation of MSCs after culture expansion have been reported in human and mouse, while very few data are present for rat MSCs (rMSCs). In this study, we monitored the chromosomal status of rMSCs at several passages in vitro, also testing the influence of
\end{abstract}

Responsible Editor: Wendy Bickmore

Dana Foudah and Serena Redaelli contributed equally to this work.

Electronic supplementary material The online version of this article (doi:10.1007/s10577-009-9090-6) contains

supplementary material, which is available to authorized users.

D. Foudah $\cdot$ S. Redaelli $\cdot$ E. Donzelli $\cdot$ A. Bentivegna

M. Miloso $\cdot$ L. Dalprà $(\bowtie) \cdot$ G. Tredici

Dipartimento di Neuroscienze e Tecnologie Biomediche,

Università degli Studi di Milano-Bicocca,

via Cadore 48,

20052 Monza, Italy

e-mail: leda.dalpra@unimib.it

L. Dalprà

US Genetica Medica, Ospedale San Gerardo,

Monza 20052, Italy four different cell culture conditions. We first used the conventional traditional cytogenetic techniques, in order to have the opportunity to observe even minor structural abnormalities and to identify low-degree mosaic conditions. Then, a more detailed genomic analysis was conducted by array comparative genomic hybridization. We demonstrated that, irrespective of culture conditions, rMSCs manifested a markedly aneuploid karyotype and a progressive chromosomal instability in all the passages we analyzed and that they are anything but stable during in vitro culture. Despite the fact that the risk of neoplastic transformation associated with this genomic instability needs to be further addressed and considering the apparent genomic stability reported for in vitro cultured human MSCs (hMSCs), our findings underline the fact that rMSCs may not in fact be a good model for effectively exploring the full clinical therapeutic potential of hMSCs.

Keywords Cytogenetic analysis · rat mesenchymal stem cells $\cdot$ chromosomal status $\cdot$ genomic stability $\cdot$ in vitro culture conditions $\cdot$ MSCs differentiation capacity

$\begin{array}{ll}\text { Abbreviations } & \\ \text { adipo } & \text { adipogenic differentiation } \\ \text { ADM2 } & \text { aberration detection method 2 } \\ \text { AIM } & \text { adipogenic induction medium } \\ \alpha-\mathrm{MEM} & \text { alpha-minimum essential medium } \\ \text { ASCs } & \text { adult stem cells } \\ \text { array-CGH } & \text { array-comparative genomic } \\ & \text { hybridization }\end{array}$


CCD-camera charge coupled device-camera

CHR

chondro

DAPI

CNVs

$\mathrm{cp}$

ct

DMEM

EAC

ES-FBS

FISH

FSC

FBS

GTG banding G-bands by trypsin and giemsa

stain

hMSCs human MSCs

mar marker

MMU mus musculus, mouse; nomencla-

ture according to Rogers et al., 2006, Genomics 87:30-38

MSCs mesenchymal stem cells

NLK

Nmyc1

OS medium

osteo

$\mathrm{P}$

PBS

QFQ banding

rMSCs

SD

SDS

SKY

SSC

sGAG

TGF- $\beta_{3}$

TMC

\section{Introduction}

Mesenchymal stem cells (MSCs) are a type of adult stem cells residing mainly in the bone marrow, and a precise definition of MSCs has been put forward by the International Society for Cellular Therapy (Dominici et al. 2006). MSCs have several advantages over the other potential stem cell candidates for cell therapy. MSCs
(1) can be easily isolated and expanded in vitro, (2) can be used autologously, (3) are hypoimmunogenic and suitable for allogeneic transplantation, (4) have immunoregulatory properties, (5) secrete a broad spectrum of bioactive macromolecules, and (6) have the capacity to migrate to the sites of injury (Caplan 2007). Moreover, MSCs have the capacity to differentiate into mesengenic lineages (osteogenic, chondrogenic, and adipogenic lineages) and to transdifferentiate into cells of nonmesodermal origin such as hepatocytes (Lee et al. 2004) and neural cells (Tondreau et al. 2008).

Several preclinical and clinical studies have confirmed the great therapeutic potential of MSCs (Brooke et al. 2007; Caplan 2007; Yu and Silva 2008; Abdallah and Kassem 2009). For clinical indications presently being tested, please see: http:// www.ClinicalTrials.gov/.

For MSCs' clinical applications, an adequate number of cells are necessary, and considering the low number of MSCs (Wexler et al. 2003; Caplan 2007), an extensive ex vivo expansion is required. The MSC culture conditions are crucial in order to maintain MSCs' morphology and biological and functional property intact for prolonged passages (Shahdadfar et al. 2005; Meuleman et al. 2006; Neuhuber et al. 2008; Pal et al. 2009). Fetal bovine serum (FBS) represents the primary source of growth supplements and bioactive compounds necessary for in vitro culture of MSCs, and most research laboratories use media containing $10-20 \%$ FBS. For the optimization of MSC cultures, various MSC culture conditions and different sources of growth supplements other than FBS have recently been evaluated (Doerr et al. 2003; Meuleman et al. 2006; Sotiropoulou et al. 2006; Mannello and Tonti 2007; Tonti and Mannello 2008; Pal et al. 2009).

Moreover, in long-term cultures, it is crucial to evaluate the safety and quality of MSCs. A number of papers have recently been published on chromosomal stability and the spontaneous transformation of MSCs, most of which are of human or mouse origin (Rubio et al. 2005; Zhou et al. 2006; Aguilar et al. 2007; Bernardo et al. 2007; Zhang et al. 2007; MezaZepeda et al. 2008; Izadpanah et al. 2008; Røsland et al. 2009). Very few data are present for rat MSCs (rMSCs; Zhou et al. 2006; Furlani et al. 2009). The importance of analyzing rMSCs is related to their use as a model for understanding their human relatives. For this purpose, we evaluated and compared the biological 
characteristics and the chromosomal status of rMSCs at several culture passages/stages. In addition, for rMSCs, we used four different cell culture conditions in order to assess some possible influencing factors on genomic stability. Firstly, we used the conventional, traditional cytogenetic techniques in order to have the opportunity to observe even minor structural abnormalities and to identify low-degree mosaic conditions. Then, a more detailed genomic analysis was conducted by array comparative genomic hybridization (array-CGH).

\section{Material and methods}

Isolation and culture of rMSCs

Animal procedures were conducted in accordance with the European Communities Council Directive 86/609/EEC. rMSCs were obtained from the bone marrow of four 10-week-old female Sprague-Dawley rats, as previously described (Donzelli et al. 2007). Total cells extracted from bone marrow (P0) were about $200 \times 10^{6}$. rMSCs were cultured in: $\alpha$-minimum essential medium ( $\alpha$-MEM) with $10 \%$ (a) or $20 \%$ (b) embryonic stem cell screened fetal bovine serum (ESFBS) and Dulbecco's modified Eagle medium (DMEM) with $10 \%$ (c) or $20 \%$ (d) ES-FBS. rMSC cultures were maintained at $37^{\circ} \mathrm{C}$ in a humidified atmosphere containing $5 \% \mathrm{CO}_{2}$. After $48 \mathrm{~h}$, the nonadherent cells were removed, and the cells attaching to the culture flasks were cultured in the four above conditions with a change of medium every 3-4 days. When rMSC cultures reached $80-90 \%$, cells were detached by using $0.25 \%$ trypsin in $0.1 \%$ ethylenediaminetetraacetic acid (EDTA) and either used in experiments or replated (one third) in $25-\mathrm{cm}^{2}$ culture flasks and expanded.

\section{Immunological characterization of rMSCs}

rMSCs (passage P1-P2) were detached by trypsinization, collected in fluorescence-activated cell sorting (FACS) tubes $\left(10^{6}\right.$ cells in each tube) and centrifuged at 1,000 rpm for $10 \mathrm{~min}$. Then, cells were decanted, washed with dilution buffer containing 3\% FBS and $0.01 \%$ sodium azide diluted in phosphate-buffered saline (PBS), and centrifuged twice at 1,000 rpm for $10 \mathrm{~min}$. Incubation with the following monoclonal antibodies was performed for $30 \mathrm{~min}$ at $4^{\circ} \mathrm{C}$ : PE-CY7 antimouse/rat CD29 (clone HMb1-1; Biolegend, San Diego, CA, USA), fluorescein isothiocyanate (FITC) antirat/mouse CD90 (clone OX-7; Biolegend, San Diego, CA, USA), PE antimouse/rat CD34 (clone ICO115; Santa Cruz Biotechnology, Inc.), biotin antirat CD45 (clone OX-1; Biolegend, San Diego, CA, USA). In other tubes, cells were incubated with the following appropriate isotype control reagents to estimate the nonspecific binding of target primary antibodies to cell surface antigens: isotype-matching IgG-FITC, IgG-PE/Cy7 (Biolegend, San Diego, CA, USA), IgG-PE (R\&D Systems, Minneapolis, MN, USA). In another single tube, cells were incubated only with PerCP-streptavidin (BD Pharmigen, Germany) without adding the primary antibody conjugated with biotin. After incubation, cells were centrifuged, decanted, and resuspended in dilution buffer three times. Analysis was performed on a flow cytometer (BD FACScanto ${ }^{\mathrm{TM}}$ FlowCytometer, BD Biosciences, San Jose, CA, USA) after the establishment of gating windows for forward light scatter and side scatter and nonspecific bindings. Data were analyzed using FACS Diva software. See Fig. S1 in Supplementary Material.

\section{Differentiation of rMSCs}

rMSCs were analyzed for their capacity to differentiate toward osteogenic, adipogenic, and chondrogenic lineages using specific protocols. rMSCs cultured in culture medium without any differentiating agents were used as a control.

Osteogenic differentiation rMSCs were seeded at approximately 3,500 cells per square centimeter on culture dishes in a culture medium composed of $\alpha$-MEM supplemented with 10\% defined FBS (lot. APC20787; Hyclone, Logan, UT, USA) until subconfluence occurred. After this period, cells were grown in culture medium alone or in osteogenic medium (OS medium) consisting of the same culture medium with the addition of the following supplements: dexamethasone $100 \mathrm{nM}$, b-glycerophosphate $10 \mathrm{mM}$ and ascorbic phosphate acid $0.05 \mathrm{mM}$. Osteogenic differentiation was evaluated by alizarin red staining to visualize calcium deposits. For a quantitative assessment of osteogenic differentiation at day 14 and at day 28 after induction, staining was quantified spectrophotometrically $\left(\mathrm{A}_{405}\right)$ after solubilization with $5 \%$ sodium dodecyl sulfate in $0.5 \mathrm{~N} \mathrm{HCl}$. 
Adipogenic differentiation rMSCs were seeded at approximately 15,000 cells per square centimeter on culture dishes in a culture medium composed of $\alpha$-MEM supplemented with $10 \%$ defined FBS. After $24 \mathrm{~h}$, cells were induced by treatment with adipogenic induction medium, consisting of $\alpha$-MEM plus $10 \%$ defined FBS supplemented with glucose $4.5 \mathrm{~g} / \mathrm{l}$, insulin $10 \mu \mathrm{g} / \mathrm{ml}$, isobutylmethylxanthine $500 \mu \mathrm{M}$, indomethacin $100 \mu \mathrm{M}$, and dexamethasone $1 \mu \mathrm{M}$. Cells treated with $\alpha$-MEM (4.5 g/l glucose) plus $10 \%$ defined FBS without other supplements represented the controls. Adipogenic differentiation was evaluated by the accumulation of lipid vacuoles using Oil Red $\mathrm{O}$ staining. For a quantitative assessment of adipogenic differentiation at day 14 and at day 28 after induction, staining was quantified spectrophotometrically $\left(\mathrm{A}_{490}\right)$ after solubilization with isopropanol.

Chondrogenic differentiation Chondrogenic differentiation was induced in cells grown as a pellet in 15-ml tubes, at approximately 250,000 cells per tube, in chondrogenic medium for about 6 weeks. Chondrogenic medium consists of $\alpha$-MEM plus $15 \%$ defined FBS with the addition of pyruvate $1 \mathrm{mM}$, dexamethasone $100 \mathrm{nM}$, ascorbic-2-phosphate acid $37.5 \mu \mathrm{g} / \mathrm{ml}$, and transforming growth factor $\beta 310 \mathrm{ng} / \mathrm{ml}$. Sections of paraffin-embedded pellets were stained with hematoxylin-eosin and safranin $\mathrm{O}$ to evaluate the formation of cartilaginous structures and the presence of proteoglycans and glycosaminoglycans. For a quantitative assessment of chondrogenic differentiation at day 14 and at day 28 after induction, pellets were digested for $16 \mathrm{~h}$ at $60^{\circ} \mathrm{C}$ with $250 \mu \mathrm{g} / \mathrm{ml}$ papain, and sulfated glycosaminoglycans (sGAG) were quantified spectrophotometrically $\left(\mathrm{A}_{530}\right)$ using the 1.9dimethyl-methylene blue method. The amount of sGAG was normalized with respect to DNA content, measured by Hoechst staining, and expressed as microgram sGAG per microgram DNA (Liebman and Goldberg 2001).

Statistical analysis Experiments for quantitative assessment of osteogenic, adipogenic, and chondrogenic differentiation were performed in triplicate. Statistical analysis was performed using the one-way ANOVA test and Tukey's multiple-comparison test as a posttest with the statistical package Graph Pad Prism (Version 3.03 for Windows, GraphPad Software, San Diego, CA, USA, www.graphpad.com).
Cytogenetic, micronuclei analysis, and molecular karyotyping

To obtain chromosome preparations, actively dividing cells from $70 \%$ to $80 \%$ confluent culture flasks were treated with colcemid $(10 \mu \mathrm{g} / \mathrm{ml})$ at a concentration of $100 \mu \mathrm{l} / \mathrm{ml}$ for $4 \mathrm{~h}$ and $30 \mathrm{~min}$ at $37^{\circ} \mathrm{C}$. After exposure to mitotic arrestant, the cells were dislodged from the flask using trypsin-EDTA $1 \times$ in PBS (Biosera) for $7 \mathrm{~min}$ at $37^{\circ} \mathrm{C}$, collected into $15-\mathrm{ml}$ centrifuge tubes, and pelleted by centrifugation at 2,000 rpm for $6 \mathrm{~min}$. The supernatant was discarded, and the pellet was suspended in $9 \mathrm{ml}$ of $0.56 \% \mathrm{KCl}$ for $12 \mathrm{~min}$ at $37^{\circ} \mathrm{C}$. Following incubation in the hypotonic, $1 \mathrm{ml}$ of freshly prepared fixative (methyl alcohol-glacial acetic acid, 3:1) was added, and the suspension was centrifuged at 2,000 rpm for $6 \mathrm{~min}$. The pelleted cells were suspended in $5 \mathrm{ml}$ of fresh fixative for $15 \mathrm{~min}$ at room temperature, and the fixative was later changed. About three drops of the cell suspension were dropped onto cold, dry slides tilted at an angle of $30^{\circ}$ and air-dried. This procedure allowed metaphase spreads in which the two chromatids of each chromosome lay close together and were relatively long (Fig. 1). Slides were stored at room temperature in a dry place and then stained for karyotype analysis.

For QFQ banding by fluorescence using quinacrine, the prepared slides were stained by immersion in a solution of quinacrine mustard $(5 \mathrm{mg} / \mathrm{ml}$ of distilled water; Sigma) for $1 \mathrm{~min}$ at room temperature, washed for $1 \mathrm{~min}$, and wet-mounted in McIlvaine's buffer under a coverslip. Metaphase chromosomes were observed with a Leica DMR fluorescent microscope, using a UV lamp, a 515-nm barrier filter, an H3 exciter filter (420-490 nm), and an immersion $\times 100$ objective. Images from the well-spread metaphases were captured using a CCD camera with dedicated software (Tesi Imaging, Italy). The karyotype was described according to the guidelines of the Committee for Standardized Karyotype of Rattus norvegicus (Committee for a Standardized Karyotype of Rattus Norvegicus 1973). At least 50 metaphases were analyzed for each passage in vitro. A chromosomal aberration was defined as clonal when at least two metaphases showed the same aberration; if the abnormality was a missing chromosome, the same change had to be present in at least three cells to be accepted as clonal. 
Fig. 1 Selected metaphase Q-banded spreads with chromosomal anomalies. a Trisomy for chromosome 6 , $[43, \mathrm{XX},+6]$; b functional trisomy for chromosome 6 , $[42, X X, \operatorname{der}(6 ; 6)]$; c trisomy for chromosome 13, $[43, \mathrm{XX},+13]$. The chromosomal anomalies are indicated by arrows
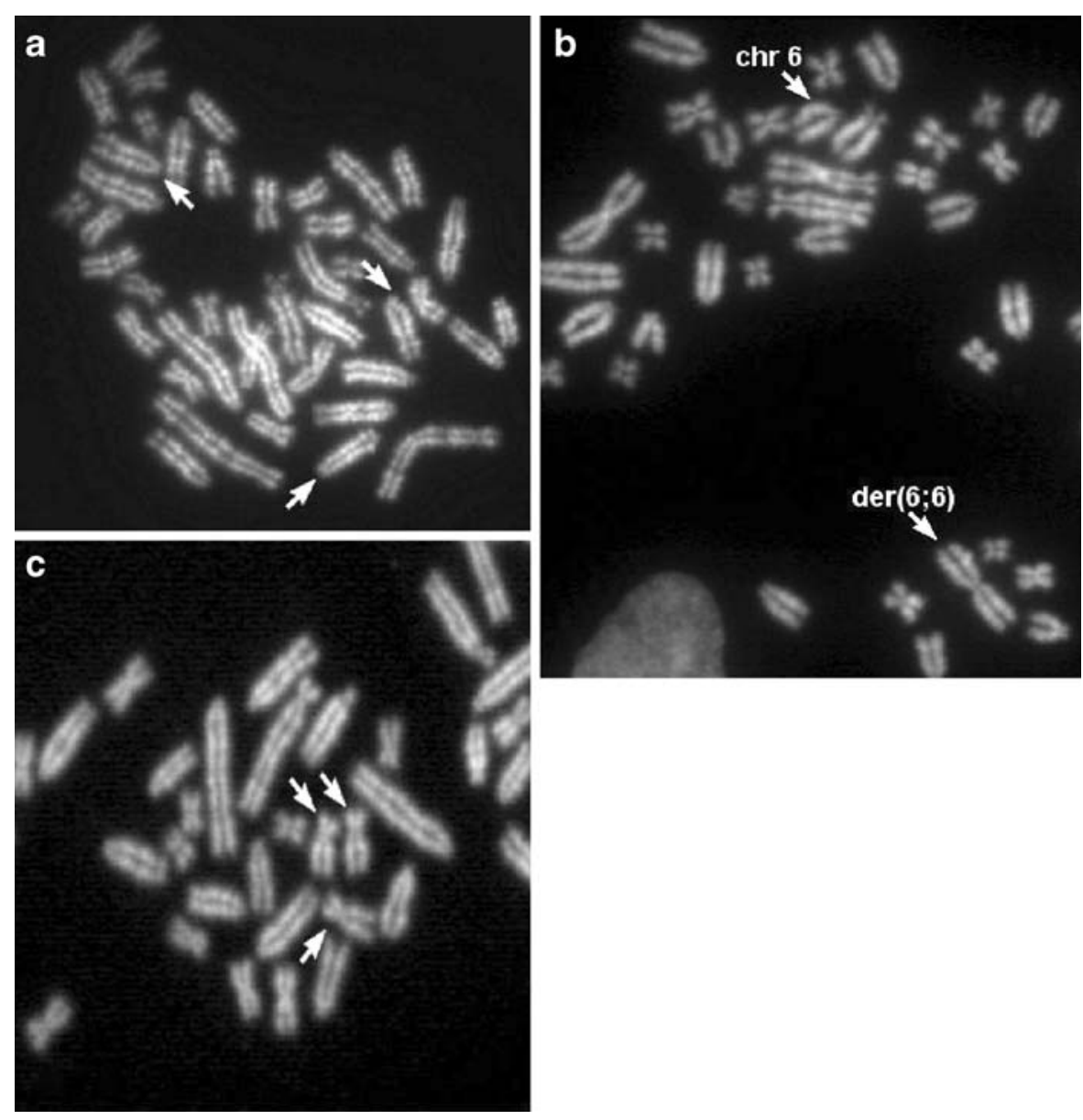

For micronuclei analysis, at least 1,000 cells were counted. Micronuclei are very small nuclei or bubbles from the nucleus that remain in the cytoplasm of the cell; they arise whenever a chromosome or a fragment of chromosome is not incorporated into one of the daughter nuclei during cell division. High frequencies of micronuclei indicate an anomaly of mitotic segregation.

Molecular karyotyping was performed through array-CGH with the Agilent kit (Rat Genome CGH Microarray 105A, Agilent Technologies) according to the manufacturer's instructions. The array-CGH platform is a 60-mer oligonucleotide-based microarray, a high-resolution tool for genome-wide DNA copy number variation profiling without amplification or complexity reduction. It has $97,000+$ coding and noncoding rat-specific sequences and $19.1 \mathrm{~KB}$ overall median probe spacing (11.3 KB in Refseq genes). The genetic situation of rMSCs from rat 8 was tested before culturing (fresh sample), just after cell isola- tion, and after 15 days' culture before passaging (defined as P0); rMSCs from rat 1 were evaluated after prolonged in vitro culture, at P4 and P24. Rat genomic DNA reference was composed of a pool of DNA extracted from cells isolated from five different Sprague-Dawley control rats after 15 days' culture before passaging. Control cell cultures were performed in 20\% FBS $\alpha$-MEM medium.

The arrays were scanned at $2-\mu \mathrm{m}$ resolution using Agilent microarray scanner and analyzed using feature extraction v10.5 and DNA analytics v4.0 software. For each spot, $\log 2$ ratios of the Cy3labeled test sample vs. Cy5 reference sample were computed and normalized by DNA Analytics 4.0 software. The Aberration Detection Method 2 (ADM2) algorithm was used to compute and assist the identification of aberrations for a given sample. In brief, ADM2 algorithm uses an iterative procedures to identify all genomic regions for which the weighted average of the measured $\log 2$ ratios from probes in 
the region deviates from its expected values of 0 by more than a given threshold. The ADM2 algorithm was applied with a threshold of 5, minimum absolute average $\log 2$ ratio in called intervals of 0.5 , and minimum of three probes. So the putative chromosome copy number changes were defined by intervals of three or more adjacent probes and were considered as duplicated or deleted when result exceeded the \pm 0.50 range.

\section{Results}

rMSC cultures

According to the criteria proposed in the definition of MSCs (Dominici et al. 2006), the MSCs isolated in our laboratory from rat bone marrow and used in our experiments, are: (a) plastic adherent and capable of extensive proliferation when maintained in standard culture conditions; (b) positive for several antigens such us CD29, CD90, and CD105 and lacking in the expression of hematopoietic surface molecules CD34 and CD45 (Fig. S1 in Supplementary Material); (c) able to differentiate into osteogenic, adipogenic, and chondrogenic lineages under specific in vitro differentiating conditions (Fig. 2). rMSCs were treated with differentiation media for 28 days, and during this period their differentiation capacity was quantitatively assessed by specific methods (see "Material and methods").

In our culture conditions (culture medium in the absence of any differentiative agents), morphological changes were also observed. At P0 and P1, rMSCs were morphologically heterogenous. From P2, rMSCs became morphologically homogenous, had a fibroblast-like phenotype, and showed a trend to become smaller with increasing passages (from P16 to forward passages). At P48, they lost their fibroblast-like phenotype (Fig. 3) but still maintained their capacity to actively divide.

rMSCs were kept in culture from P0 to P48 that corresponded to about 35 weeks (238 days) of culture. Cells were passaged 1:3 after reaching $80-90 \%$ of confluence. The time required to achieve $80-90 \%$ of confluence differed depending on the passage number: 2 weeks for P0 and P1, 1 week for passages between P2 and P15, and only 3-4 days for P16 and forward passages. These data referred to cells cultured in $\alpha$-MEM (or DMEM) containing $20 \%$ of FBS. The times required for cells cultured with $10 \%$ of FBS were double those obtained in $20 \%$ FBS. The differentiation capacity was quantitatively assessed at passages 1, 4, 8, 16, 24, and 48 as shown in Fig. 4. Osteogenic capacity (Fig. 4a) was increased at 28 days for almost all the passages analyzed. Adipogenic differentiation (Fig. 4b) was observed in most of the passages examined, but it was enhanced after 14 days of treatment. Chondrogenic differentiation (Fig. 4c) after 28 days of treatment was more evident at passages 8,24 , and 48 .

\section{Cultured rMSCs karyotype}

The modal number of chromosomes (i.e., those most highly represented in a population that has several aneuploid cell clones) tended to deviate from the normal karyotype 42,XX (Table 1), starting from early passages (already from P1) while at P0, both at one and at 15 days after isolation, regardless of the culture conditions, the normal modal number of chromosomes was, in general, conserved (Table 2). The percentages of cells with micronuclei and metaphases with random loss (i.e., signs of genomic instability) were widely variable, although the common trend was towards a reduction with increasing in vitro passages. These changes appeared to be independent of the culture conditions (Table 3). Aneuploid cells increased with increasing passages, i.e., for animal 1 at P48, almost all cells (96.4\%) were aneuploid with at least one clonal numeric aberration (Table 1 and Fig. 5a). In addition, a slight correlation between the percentages of cells with a clonal chromosomal anomaly and the culture media emerged, as demonstrated for two animals in Fig. $5 b$, c where in both cases $\alpha$-MEM was found to be the most stabilizing medium. Regarding the anomalies, the trisomies were more frequent than the monosomies. In particular, the monosomy of chromosome 20 recurred in two animals. The trisomies involved ten different chromosomes, but only the $13 \mathrm{~s}$ and, to a minor degree, the $6 \mathrm{~s}$ were frequently observed in different animals (Table 1 and Fig. 1). In order to assess if this bizarre in vitro behavior was a prerogative or not of rMSCs, we monitored, in a similar way, the karyotype of hMSCs. We never found any clonal numeric aberration nor clonal structural aberration until passage 16 (data not 
Fig. 2 rMSC differentiation. Osteogenic differentiation.

Alizarin red staining of rMSCs cultured for 28 days in $\alpha$-MEM supplemented with $10 \%$ defined FBS (control, a) or in OS medium. (b) Adipogenic differentiation. Oil Red O staining of rMSCs cultured for 28 days in $\alpha$ MEM (4.5 g/l glucose) supplemented with $10 \%$ defined FBS (control, c) or in adipogenic induction medium (d). Bars $50 \mu \mathrm{m}$. Chondrogenic differentiation. Safranin O staining of paraffin-embedded sections of rMSCs cultured in pellets for 6 weeks in $\alpha$-MEM supplemented with $15 \%$ defined FBS (control, e) or with chondrogenic induction medium (f). Bars $50 \mu \mathrm{m}$
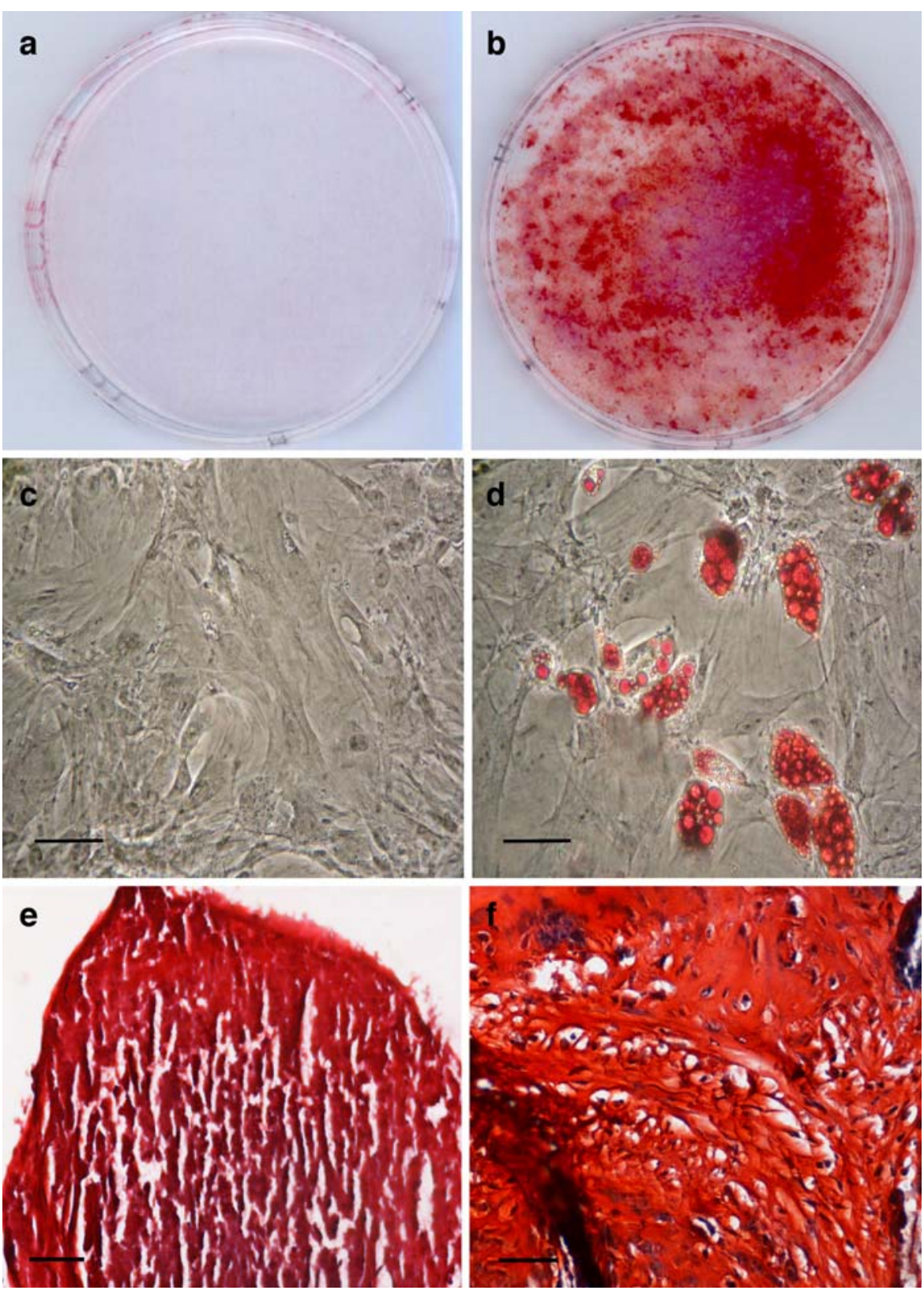

shown), confirming the general chromosomal stability reported in literature for these cells (Aguilar et al. 2007; Bernardo et al. 2007; Zhang et al. 2007).

Finally, we performed molecular karyotyping by means of array-CGH on rMSCs. We analyzed the genomic status of rMSCs through the competition with a genomic pool of rMSCs after 15 days of culture, from five different rats, in order to have as suitable as possible a reference for our array-CGH experiments. The array contained a library of probes selected from the rat genome database. We analyzed the genomic status of a control Sprague-Dawley rat (rat 8): (1) immediately after cell isolation (fresh sample) and (2) after 15 days postisolation cell culture; and of rat 1 (in addition to conventional karyotyping): (3) at culture passage P4 and (4) at culture passage P24; the data are summarized in Fig. 6 and in Table S1 in Supplementary Material. We identified 37 copy number variants (CNVs), 19 gains and 18 losses, covering at least $120 \mathrm{Mb}$, with sizes ranging from $12.8 \mathrm{~kb}$ (an heterozygous loss of rat 1 $\mathrm{P} 4$ and P24) to more than $100 \mathrm{Mb}$ for chromosome 13 

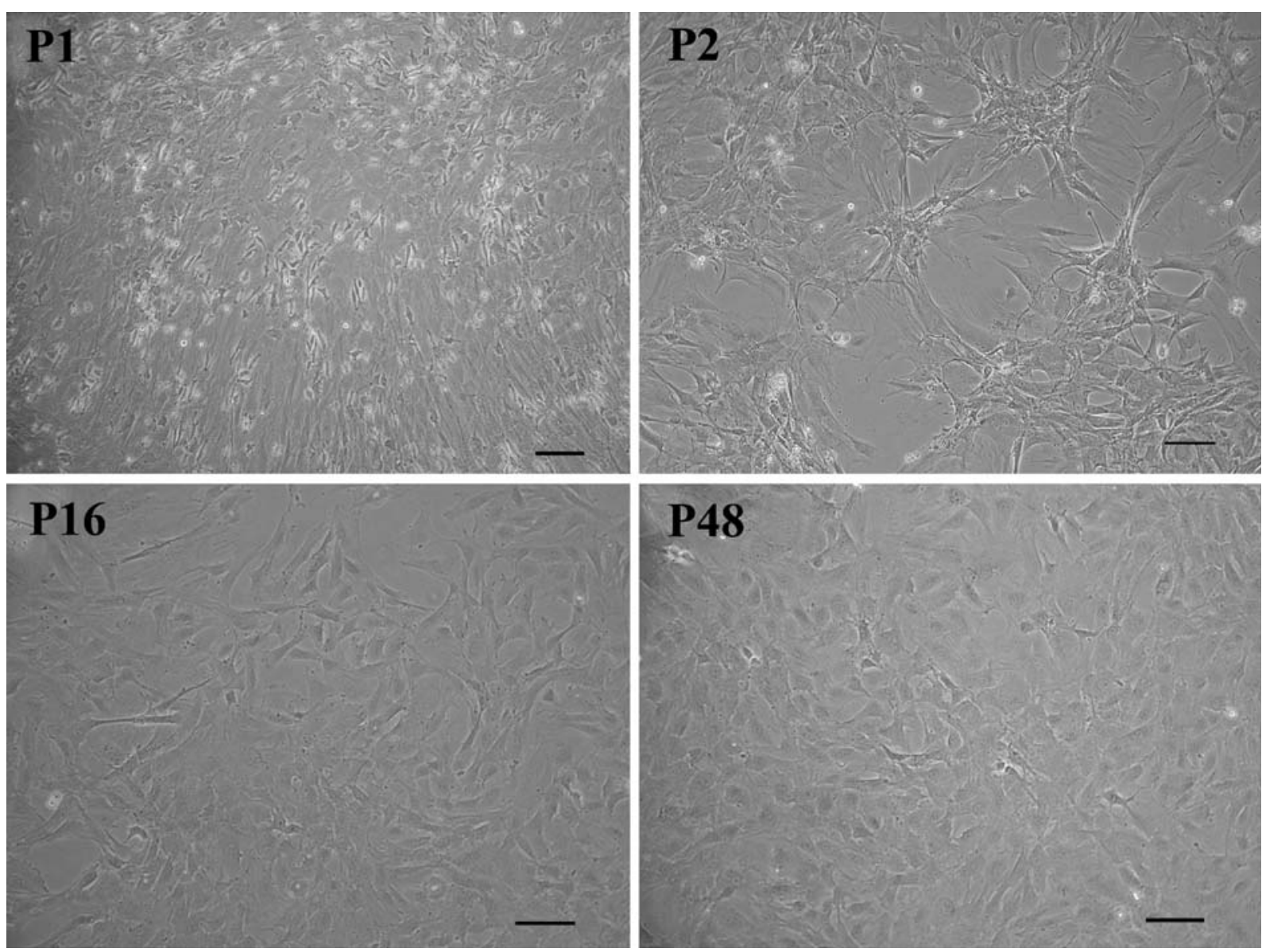

Fig. 3 rMSC cultures. rMSC cultures displayed different morphology according to the passage number: at P1 rMSC cultures were still heterogenous; at P2, they became homogenous, characterized by the presence of cells with a fibroblast-like phenotype; at P16, they were already morphologically homoge-

trisomy of rat 1 at $\mathrm{P} 24$, still identified by conventional karyotyping. For rat 8 , we observed a total of 14 gains versus ten losses, while for rat 1, 11 gains and 12 losses were detected. Eleven CNVs identified in our work were recently identified in a rat genome-wide study by two other microarray platforms (Guryev et al. 2008), and five out of these 11 were also detected in both rats analyzed. Notably, we found the presence of an instable region of $381 \mathrm{~Kb}$ on chromosome $6 \mathrm{q} 33$ observing 23 consecutive probes, alternately as gain or loss (see Table S1 in Supplementary Material). Another CNV, a gain of $795.8 \mathrm{~kb}$ in $\mathrm{Xq} 35$, in the same CNV region annotated by Guryev et al. 2008, was detected both in rat 1 and in rat 8 but, in the latter, it was evidenced only after cell isolation (in a fresh sample) while, after 15 days postisolation cell

nous, but cells seemed to be smaller in size with respect to previous passages; at P48, cells lost their fibroblastic-like shape, appearing more rounded and forming a homogenous monolayer film. Bars $100 \mu \mathrm{m}$

culture, it was absent, showing again genomic instability when these cells were cultured in vitro (see Table S1 in Supplementary Material for other examples).

\section{Discussion}

This is the first time, to our knowledge, that such a thorough and complete study on the genomic stability of rMSCs has been carried out, by means of cytogenetic characterization and molecular karyotyping. We used both a conventional, traditional cytogenetic technique and an array-CGH platform, in order to have the opportunity to observe also balanced structural abnormalities and to identify 


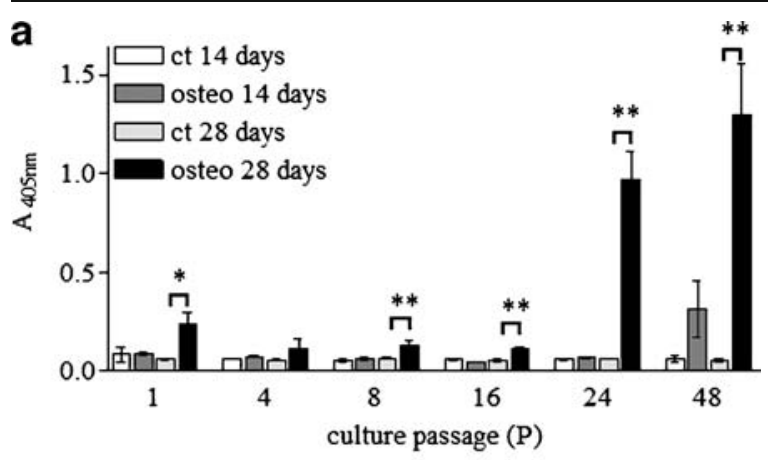

b
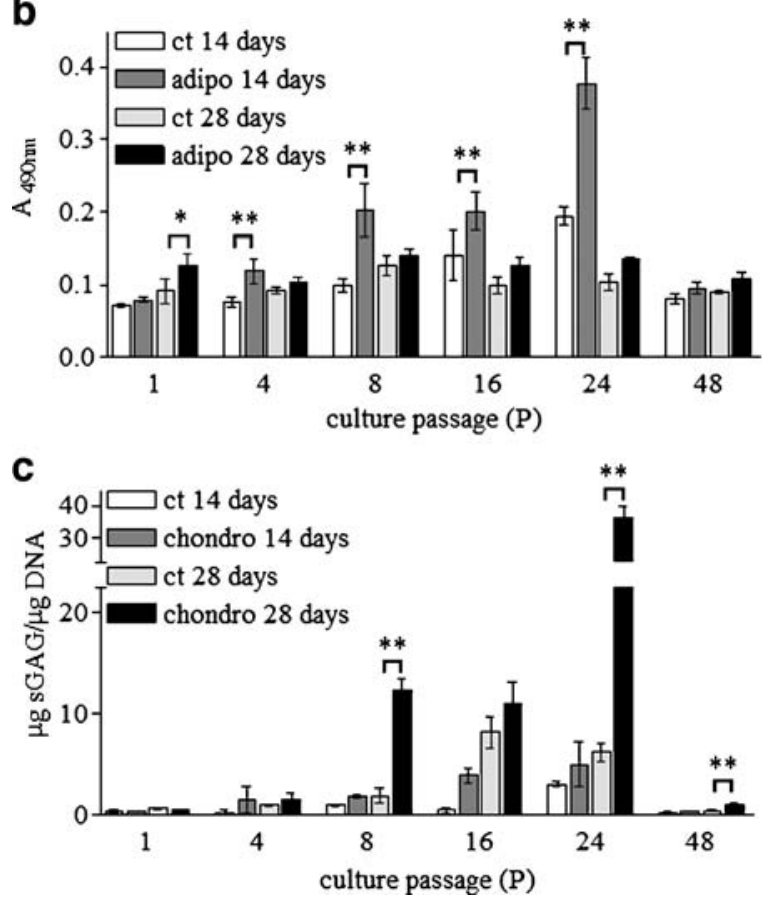

Fig. 4 rMSC differentiation quantitative assessment. rMSC at different passages were treated for a osteogenic differentiation (osteo); b adipogenic differentiation (adipo); c chondrogenic differentiation (chondro) for 14 or 28 days, and quantitative assessment of differentiation was performed. For each treatment, rMSCs cultured in culture medium without any differentiating agents were used as a control $(c t)$. Experiments were performed in triplicate and results are expressed as mean $\pm \mathrm{SD}$. ${ }^{*} p<0.05: * * p<0.01$

low-degree mosaic conditions, something which the more advanced techniques are not able to do. We demonstrated that, irrespective of culture conditions, rMSCs manifested a markedly aneuploid karyotype and a chromosomal instability in all the passages we analyzed and that they are anything but stable during in vitro culture.

Despite their chromosomal instability, rMSC differentiation capability is not affected. In fact, rMSCs are able to differentiate into mesengenic lineages in the culture passages in which genomic instability has been demonstrated. This finding does not exclude that other biological properties of rMSCs can be modified consequently to the altered genomic stability. Regarding the maintenance of these properties, similar findings are reported in literature for adult and embryonic mouse neural stem cells (Goffredo et al. 2008; Spiliotopoulos et al. 2009).

Several studies on MSCs from different sources have highlighted how genomic instability could lead to spontaneous immortalization and malignant transformation (see Table S2 in Supplementary Material for a literature review). In particular, spontaneous transformation of MSCs after in vitro culture expansion has been reported in human adipose-derived MSCs (Rubio et al. 2005; Wang et al. 2005) and in mouse bone-marrow-derived MSCs (Miura et al. 2006; Zhou et al. 2006; Aguilar et al. 2007; Tolar et al. 2007). Only two studies to date have reported on the chromosomal status of cultured rMSCs (Zhou et al. 2006; Furlani et al. 2009). The former, by GTG banding at $\mathrm{P} 6$, revealed that the majority of these cells maintained the normal number of 42 rat chromosomes with no translocations, although three out of the 50 cells analyzed were tetraploid (84 chromosomes). The latter, on the contrary, is completely in agreement with our results as the authors demonstrated that rMSCs, cultured under standard conditions, could undergo transformation in the early passages (at P3), and these observations were derived from a simple counting of chromosome numbers following Giemsa staining. The data we collected were derived from a more detailed karyotype analysis on rMSCs from different animals, in vitro expanded under four culture conditions, and monitored at several passages in culture; furthermore, we also had the opportunity to compare the data obtained by arrayCGH analysis, a technique for high-resolution genomic studies, on fresh rMSCs (immediately after cell isolation) and after culture expansion, derived from the same animal. Our results indicate that in vitro cultured rMSCs showed a progressive chromosomal instability associated with an increased rate of proliferation.

As many studies have evidenced the close correlation between chromosome instability, spontaneous transformation, and cancer initiation (Rubio et al. 2005; Wang et al. 2005; Zhou et al. 2006; 
Table 1 Karyotype in vitro evolution of rMSCs from four rats cultured in four different media

\begin{tabular}{|c|c|c|c|c|c|c|}
\hline Medium & $\begin{array}{l}\text { Culture } \\
\text { passage }\end{array}$ & Animal & $\begin{array}{l}\% \\
\text { normal }\end{array}$ & $\%$ with clonal numeric aberration & $\%$ with structural aberration & $\begin{array}{l}\% \text { with random } \\
\text { loss/gain }\end{array}$ \\
\hline \multirow{16}{*}{$\begin{array}{l}\alpha \mathrm{MEM} \\
20 \% \text { FBS }\end{array}$} & \multirow[t]{2}{*}{$1^{\circ}$} & 3 & 67.3 & $6.1(41, X X,-20)$ & 0 & 26.6 \\
\hline & & 4 & 51.7 & $5(41, X X,-20)$ & 0 & 43.3 \\
\hline & \multirow[t]{2}{*}{$4^{\circ}$} & 1 & 67.2 & $8.2(43 \sim 44, \mathrm{XX},+13,+13, \mathrm{cp}[4])$ & 0 & 24.6 \\
\hline & & 4 & 77.8 & 0 & 0 & 22.2 \\
\hline & \multirow[t]{4}{*}{$8^{\circ}$} & 1 & 9.2 & $66.7(43 \sim 44, \mathrm{XX},+13,+13, \mathrm{cp}[33])$ & 0 & 24.1 \\
\hline & & 2 & 67.5 & $15(43 \sim 44, \mathrm{XX},+13,+13, \mathrm{cp}[8])$ & 0 & 17.5 \\
\hline & & 3 & 56.8 & $27(43, X X,+13)$ & 0 & 16.2 \\
\hline & & 4 & 76 & 0 & 0 & 24 \\
\hline & \multirow[t]{4}{*}{$16^{\circ}$} & 1 & 1.7 & $54.2(43, \mathrm{XX},+13)$ & $37.3(42, \mathrm{XX}, \operatorname{der}(2 ; 15))$ & 6.8 \\
\hline & & 2 & 28 & $40(43 \sim 44, X X,+11,+13, \mathrm{cp}[20])$ & 0 & 32 \\
\hline & & 3 & 29.6 & $42.6(43, \mathrm{XX},+10,+13, \mathrm{cp}[23])$ & $\begin{array}{l}1.8(44, \mathrm{XX},+13, \mathrm{t}(3 ; 11), \operatorname{der} 3 \mathrm{p}) ; 1.8 \\
(42, \mathrm{XX},+13,-16, \mathrm{t}(3 ; 4))\end{array}$ & 24.2 \\
\hline & & 4 & 69 & $5.8(41, X X,-20)$ & 0 & 25.2 \\
\hline & \multirow[t]{3}{*}{$24^{\circ}$} & 1 & 0 & $91.7(43 \sim 44, X X,+13,+13, \mathrm{cp}[46])$ & $2.7(42, \mathrm{XX}, \operatorname{der}(2 ; 15))$ & 5.6 \\
\hline & & 3 & 0 & $92.2(43, \mathrm{XX},+13)$ & 0 & 7.8 \\
\hline & & 4 & 3.8 & $\begin{array}{l}26.4(41 \sim 85, \mathrm{XXXX},-20,+10,+13, \\
\operatorname{cp}[14])\end{array}$ & 0 & 69.8 \\
\hline & $48^{\circ}$ & 1 & 1.8 & $96.4(43 \sim 44, X X,+13,+13, \mathrm{cp}[48])$ & 0 & 1.8 \\
\hline \multirow{9}{*}{$\begin{array}{l}\alpha \mathrm{MEM} \\
10 \% \text { FBS }\end{array}$} & \multirow[t]{2}{*}{$1^{\circ}$} & 3 & 60 & $8.2(41, X X,-20)$ & $2(42, X X, \operatorname{der}(6 ; 6))$ & 29.8 \\
\hline & & 4 & 76 & 0 & 0 & 24 \\
\hline & \multirow[t]{2}{*}{$4^{\circ}$} & 3 & 73.6 & $11.1(43, X X,+13)$ & 0 & 15.3 \\
\hline & & 4 & 66.8 & 0 & 0 & 33.2 \\
\hline & \multirow[t]{2}{*}{$8^{\circ}$} & 3 & 30.6 & $27(43, \mathrm{XX},+13)$ & $9.4(42, X X, \operatorname{der}(6 ; 6))$ & 33 \\
\hline & & 4 & 60 & $6.65(43, X X,+18)$ & $6.65(43, \mathrm{XX},+$ mar $)$ & 26.7 \\
\hline & \multirow[t]{2}{*}{$16^{\circ}$} & 3 & 0 & $5.6(41, X X, \operatorname{der}(6 ; 6),-20)$ & $92.6(42, \mathrm{XX}, \operatorname{der}(6 ; 6))$ & 1.8 \\
\hline & & 4 & 0 & $\begin{array}{l}45.7(79 \sim 88, \mathrm{XXXX},-20,+4,+5,+6 \\
+7,+10,+11,+12, \operatorname{cp}[16])\end{array}$ & $\begin{array}{l}37.1(85 \sim 87, \mathrm{XXXX},+ \text { mar1, }+ \text { mar2, } \\
\operatorname{cp}[13])\end{array}$ & 17.2 \\
\hline & $24^{\circ}$ & 3 & 0 & $\begin{array}{l}15.7(43 \sim 46, X X, \operatorname{der}(6 ; 6),+3,+6 \\
+12,+13, \mathrm{cp}[8])\end{array}$ & $80.4(42, X X, \operatorname{der}(6 ; 6))$ & 3.9 \\
\hline \multirow{4}{*}{$\begin{array}{l}\text { DMEM } \\
20 \% \mathrm{FBS}\end{array}$} & $1^{\circ}$ & 4 & 80.4 & 0 & 0 & 19.6 \\
\hline & $4^{\circ}$ & 4 & 78.3 & $4.3(43, \mathrm{XX},+13)$ & 0 & 17.4 \\
\hline & $8^{\circ}$ & 4 & 50 & 0 & $10(42, X X, 1$ dicen $)$ & 40 \\
\hline & $16^{\circ}$ & 4 & 1.8 & 0 & $76(42, X X, 5 p+)$ & 22.2 \\
\hline \multirow{8}{*}{$\begin{array}{l}\text { DMEM } \\
10 \% \mathrm{FBS}\end{array}$} & \multirow[t]{2}{*}{$1^{\circ}$} & 3 & 69 & $10.3(41, X X,-20)$ & $1.7(42, X X, \operatorname{der}(5 ; 18))$ & 19 \\
\hline & & 4 & 33.3 & 0 & 0 & 66.7 \\
\hline & \multirow[t]{2}{*}{$4^{\circ}$} & 3 & 79.5 & 0 & 0 & 20.5 \\
\hline & & 4 & 6.7 & $76.6(43 \sim 44, \mathrm{XX},+6,+13, \mathrm{cp}[23])$ & $3.3(45, \mathrm{XX},+11,+13,+14,1$ dicen $)$ & 13.4 \\
\hline & \multirow[t]{2}{*}{$8^{\circ}$} & 3 & 32.4 & $38.2(43, \mathrm{XX},+6,+7, \mathrm{cp}[26])$ & $13.2(42, \mathrm{XX}, 2 \mathrm{p}+)$ & 16.2 \\
\hline & & 4 & 2 & $\begin{array}{l}68(43 \sim 48, X X,+3,+7,+12,+13,+14, \\
\operatorname{cp}[34])\end{array}$ & 0 & 30 \\
\hline & $16^{\circ}$ & 4 & 0 & $\begin{array}{l}73.2(46 \sim 48, X X,+3,+4,+6,+7,+12 \\
+13,+14, \operatorname{cp}[38])\end{array}$ & 0 & 26.8 \\
\hline & $24^{\circ}$ & 3 & 2 & $92(43 \sim 44, X X,+3,+7,+13, \mathrm{cp}[46])$ & 0 & 6 \\
\hline
\end{tabular}

The percentages refer to the total number of metaphases analyzed; at least 50 metaphases were analyzed for each passage. For some culture passages, a great karyotypic heterogeneity was observed and composite karyotypes ( $\mathrm{cp}$ ) were created. These cp contained all clonally observed abnormalities and gave the range of chromosome numbers in the cells containing the clonal aberrations. The number of cells in which the clonal changes were observed was given in square brackets after the karyotype 
Table 2 Karyotype of rMSCs from control rats at P0 cultured in four different media

\begin{tabular}{|c|c|c|c|c|c|c|}
\hline Medium & $\begin{array}{l}\text { Days after } \\
\text { isolation }\end{array}$ & Animal & $\%$ normal & $\begin{array}{l}\% \text { with clonal } \\
\text { numeric aberration }\end{array}$ & $\begin{array}{l}\% \text { with structural } \\
\text { aberration }\end{array}$ & $\begin{array}{l}\% \text { with random } \\
\text { loss/gain }\end{array}$ \\
\hline \multirow[t]{15}{*}{$\alpha \mathrm{MEM} 20 \% \mathrm{FBS}$} & \multirow[t]{6}{*}{1} & 5.09 & 96 & 0 & 0 & $4 / 0$ \\
\hline & & 6.09 & 88 & 0 & 0 & $12 / 0$ \\
\hline & & 7.09 & 85.3 & 0 & 0 & $11.8 / 2.9$ \\
\hline & & 8.09 & 82.4 & 0 & 0 & $17.6 / 0$ \\
\hline & & 9.09 & 82.4 & 0 & 0 & $17.6 / 0$ \\
\hline & & 10.09 & 86.3 & 0 & 0 & 11.8/1.9 \\
\hline & \multirow[t]{9}{*}{15} & 5 & 44.4 & 0 & 0 & $48.1 / 7.5$ \\
\hline & & 6 & 81.5 & 0 & 0 & $14.8 / 3.7$ \\
\hline & & 7 & 78.4 & 0 & 0 & $19.6 / 2$ \\
\hline & & 5.09 & 85 & 0 & 0 & $7.5 / 7.5$ \\
\hline & & 6.09 & 76 & 0 & 0 & $22 / 2$ \\
\hline & & 7.09 & 86.8 & 0 & 0 & $7.5 / 5.7$ \\
\hline & & 8.09 & 76.5 & 0 & 0 & $23.5 / 0$ \\
\hline & & 9.09 & 63.7 & 0 & 0 & $33.3 / 3$ \\
\hline & & 10.09 & 78 & 0 & 0 & $16 / 6$ \\
\hline \multirow[t]{3}{*}{$\alpha$-MEM $10 \%$ FBS } & \multirow[t]{3}{*}{15} & 5 & 75 & 0 & 0 & $25 / 0$ \\
\hline & & 6 & 72.5 & 0 & 0 & $25.2 / 2$ \\
\hline & & 7 & 52.9 & 0 & 0 & $43.1 / 4$ \\
\hline \multirow[t]{3}{*}{ DMEM $20 \%$ FBS } & \multirow[t]{3}{*}{15} & 5 & 69 & 0 & 0 & $27.6 / 3.4$ \\
\hline & & 6 & 48.1 & 0 & 0 & $50 / 1.9$ \\
\hline & & 7 & 72.5 & 0 & 0 & $25.4 / 2.1$ \\
\hline \multirow[t]{3}{*}{ DMEM 10\% FBS } & \multirow[t]{3}{*}{15} & 5 & 83.3 & 0 & 0 & $16.7 / 0$ \\
\hline & & 6 & 44.2 & $5.8(41, X) ; 5.8(41, X X,-20)$ & 0 & $44.2 / 0$ \\
\hline & & 7 & 68 & 0 & $2(43, \mathrm{XX},+\mathrm{mar})^{\mathrm{a}}$ & $20 / 10$ \\
\hline
\end{tabular}

${ }^{\mathrm{a}}$ Not clonal

Aguilar et al. 2007; Tolar et al. 2007), we searched the resulting abnormal karyotypic regions in silico for genes that might be important for cell cycle regulation. Interestingly, on chromosome 13, which was the most frequently involved in karyotype aberrations and in rat 1 is even present in triplicate, was mapped the predicted RGD1561440 (http:// www.ensembl.org/Rattus_norvegicus/), this being similar to the human nemo-like kinase gene (NLK) and necessary for the differentiation of bone marrow stromal cells. The human NLK negatively regulates the Wnt/beta-catenin signaling pathway and the Myb transcription factor (see The UniProt Consortium: http://www.uniprot.org/uniprot/Q9UBE8). Moreover, on chromosome 13, many other genes are mapped which are involved in cell cycle regulation and in malignant transformation (e.g., oncogenes Abl2, Bcl2, Mapkapk2; http://www.ensembl.org/
Rattus_norvegicus/), suggesting that aberrations of chromosome 13 may lead to changes in the biological properties of rMSCs which are important for their normal functioning and which could predispose them to malignant transformation.

Similarly, for chromosome 6 , which was found to be involved in a functional trisomy, the $\operatorname{der}(6 ; 6)$, both by conventional karyotyping and by array-CGH analysis, real outbreak of gain and loss of CNVs was found to have taken place. It is interesting to note that one common aberration detected in a rat model of endometrial adenocarcinoma is a gain/amplification affecting the proximal part of this chromosome (RNO6) including three cancer-related genes: Ddx1, Rrm2, and Mycn (Adamovic et al. 2005). Mouse neuroblastoma myc-related oncogene 1 (Nmyc1) possesses transcription factor activity that plays a role in cell cycle regulation. MYCN is known to be 
Table 3 Micronuclei counting of rMSCs of four rats cultured in four different media

\begin{tabular}{|c|c|c|c|c|}
\hline Animal & Medium & $\begin{array}{l}\text { Culture } \\
\text { passage }\end{array}$ & $\begin{array}{l}\text { \% normal } \\
\text { nuclei }\end{array}$ & $\begin{array}{l}\% \\
\text { micronuclei }\end{array}$ \\
\hline \multirow[t]{5}{*}{1} & \multirow[t]{5}{*}{$\alpha \mathrm{MEM} 20 \%$ FBS } & $4^{\circ}$ & 54.5 & 45.5 \\
\hline & & $8^{\circ}$ & 80.4 & 19.6 \\
\hline & & $16^{\circ}$ & 86.8 & 13.2 \\
\hline & & $24^{\circ}$ & 88 & 12 \\
\hline & & $48^{\circ}$ & 91.2 & 8.8 \\
\hline \multirow[t]{6}{*}{2} & \multirow[t]{6}{*}{$\alpha \mathrm{MEM} 20 \%$ FBS } & $4^{\circ}$ & 69.7 & 30.3 \\
\hline & & $8^{\circ}$ & 85 & 15 \\
\hline & & $1^{\circ}$ & 83.4 & 16.6 \\
\hline & & $8^{\circ}$ & 65.8 & 34.2 \\
\hline & & $16^{\circ}$ & 30.6 & 60.4 \\
\hline & & $24^{\circ}$ & 49.3 & 50.7 \\
\hline \multirow[t]{9}{*}{3} & \multirow[t]{5}{*}{$\alpha \mathrm{MEM} 10 \%$ FBS } & $1^{\circ}$ & 80.7 & - \\
\hline & & $5^{\circ}$ & 43.9 & 56.1 \\
\hline & & $8^{\circ}$ & 29.4 & 70.6 \\
\hline & & $16^{\circ}$ & 19.8 & 80.2 \\
\hline & & $24^{\circ}$ & 30.2 & 69.8 \\
\hline & \multirow[t]{4}{*}{ DMEM 10\% FBS } & $1^{\circ}$ & 82.2 & 17.8 \\
\hline & & $5^{\circ}$ & 64.2 & 35.8 \\
\hline & & $8^{\circ}$ & 76 & 24 \\
\hline & & $24^{\circ}$ & 66.9 & 33.1 \\
\hline \multirow[t]{17}{*}{4} & \multirow[t]{5}{*}{$\alpha$ MEM $20 \%$ FBS } & $1^{\circ}$ & 41.4 & 58.6 \\
\hline & & $4^{\circ}$ & 31.1 & 68.9 \\
\hline & & $8^{\circ}$ & 38.3 & 61.7 \\
\hline & & $16^{\circ}$ & 59 & 41 \\
\hline & & $24^{\circ}$ & 47.2 & 52.8 \\
\hline & \multirow[t]{4}{*}{$\alpha \mathrm{MEM} 10 \%$ FBS } & $1^{\circ}$ & 34.3 & 65.7 \\
\hline & & $4^{\circ}$ & 27.1 & 72.9 \\
\hline & & $8^{\circ}$ & 44.4 & 55.6 \\
\hline & & $16^{\circ}$ & 37.8 & 62.2 \\
\hline & \multirow[t]{4}{*}{ DMEM $20 \%$ FBS } & $1^{\circ}$ & 45.8 & 54.2 \\
\hline & & $4^{\circ}$ & 63.1 & 36.9 \\
\hline & & $8^{\circ}$ & 46.1 & 53.9 \\
\hline & & $16^{\circ}$ & 70.5 & 29.5 \\
\hline & \multirow[t]{4}{*}{ DMEM 10\% FBS } & $1^{\circ}$ & 38.6 & 61.4 \\
\hline & & $4^{\circ}$ & 44.1 & 55.9 \\
\hline & & $8^{\circ}$ & 49.4 & 50.6 \\
\hline & & $16^{\circ}$ & 66.4 & 33.6 \\
\hline
\end{tabular}

At least 1,000 nuclei were analyzed for each passage
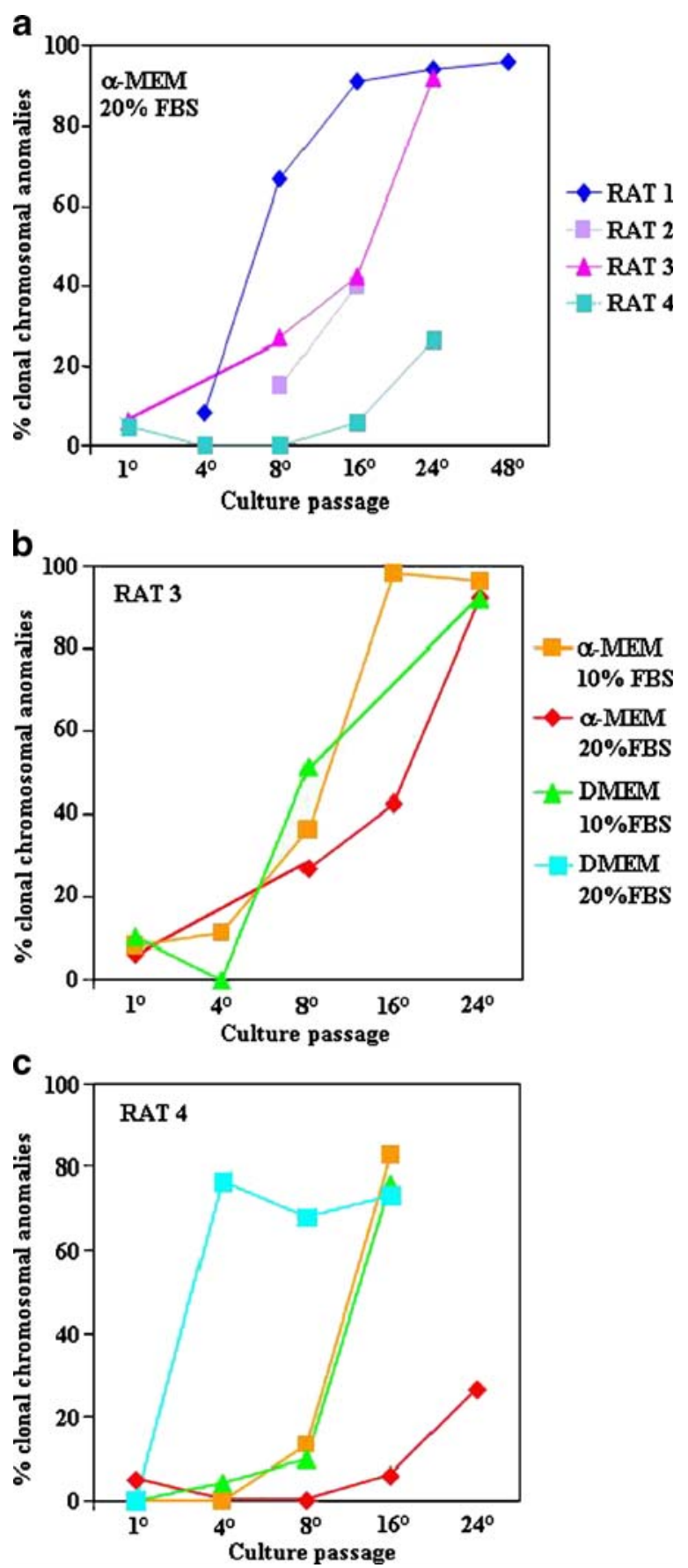

Fig. 5 Percentage of metaphases with clonal chromosomal anomalies (both aneuploidies and structural aberrations) versus passage progression. a Rats $1-2-3-4$ in $\alpha$-MEM $20 \% \mathrm{FBS}$; b rat 3 in $\alpha$-MEM $20 \%$ FBS, $\alpha$-MEM $10 \%$ FBS, DMEM $10 \%$ FBS; c Rat 4 in all the culture conditions used in this study 


\section{a Rat 1 P4}
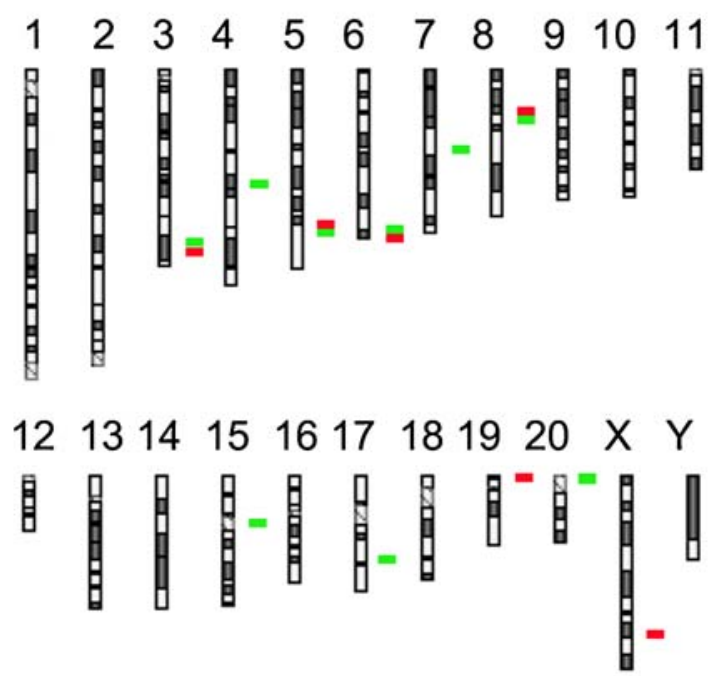

\section{Rat 1 P24}
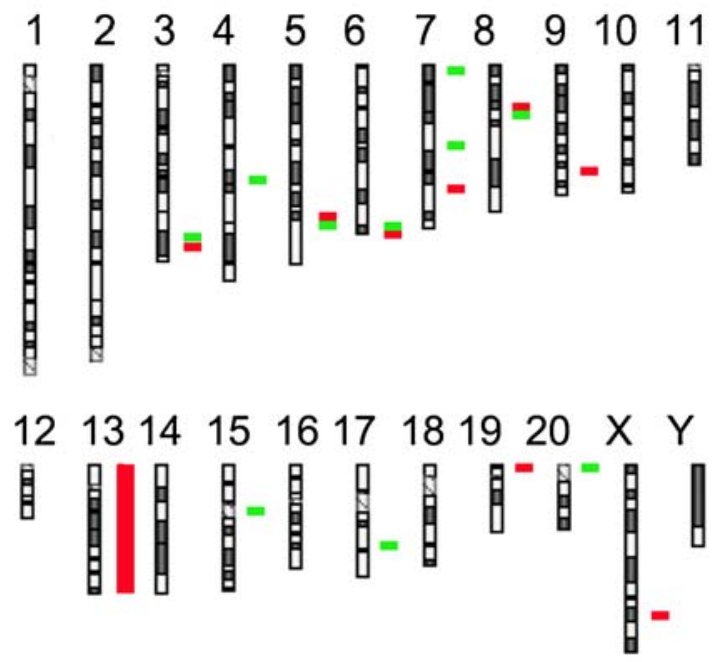

\section{b Rat 8 freshly isolated cells}

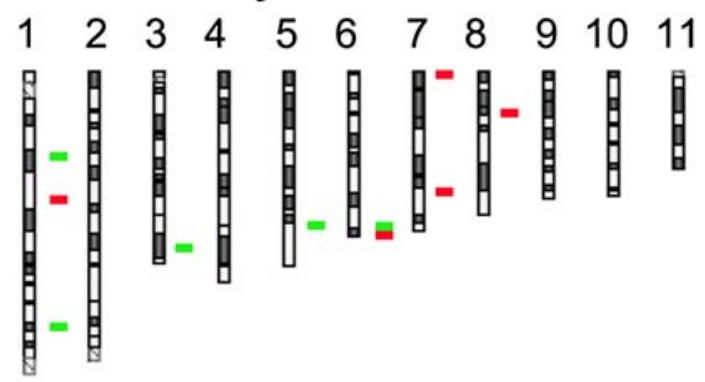

\section{Rat 8 P0 (2 weeks culture)}
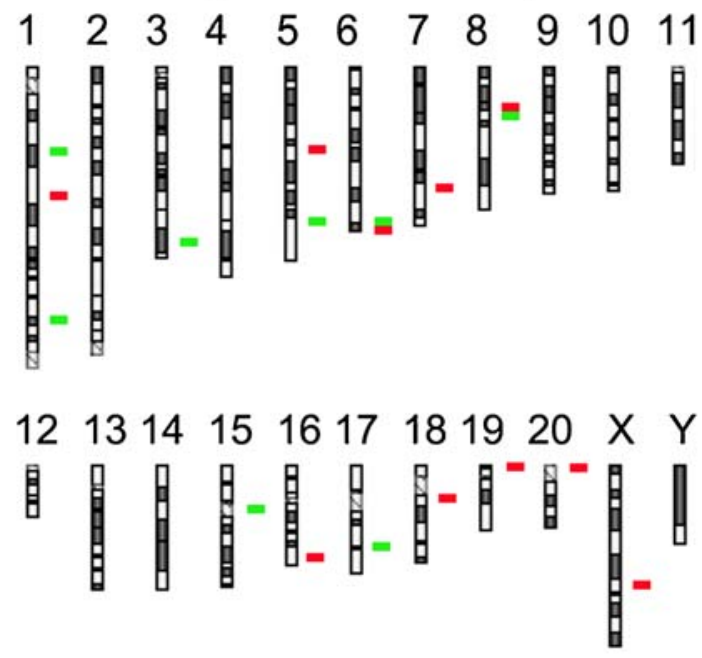

\section{Gain compared to reference} Loss compared to reference

Fig. 6 Chromosomal distribution of $\mathrm{CNV}$ regions detected by array comparative genomic hybridization (array-CGH) on rMSCs of a rat 1 at P4 (top) and P24 (bottom); b rat 8 freshly isolated cells (top) and 2 weeks culture (bottom). Colors

amplified in human neuroblastomas, in several other human tumors (Brodeur et al. 1984; Rubie et al. 1997), and in mouse medulloblastomas (Shakhova et al. 2006). Similarly, increased c-myc expression, the most famous member of the myc-family, has recently been described in mouse bone marrow MSCs and in human adipose MSCs; in both cases, continuous passaging led MSCs to spontaneous immortalization represent the type of chromosomal aberration: red (region with gain compared to reference); green (region with loss compared to reference). See Table S1 in Supplementary material and the text for more details

and transformation into malignant cells, suggesting a role for this gene in these processes. So, we could speculate that there is a possible risk of neoplastic transformation where there is a gain/amplification of rat chromosome 6.

Finally, our results support the idea that there is a considerable risk for long-term rMSC cultures as the genomic instability has been amply demonstrated. 
Despite the fact that the risk of neoplastic transformation associated with this genomic instability needs to be further addressed and considering the apparent genomic stability reported for in vitro cultured hMSCs (see Table S2 in Supplementary Material), our findings underline the fact that rMSCs may not in fact be a good model for effectively exploring the full clinical therapeutic potential of hMSCs.

Acknowledgements The authors would like to thank Dr. R. Rigolio for carrying out the flow cytometric analysis and Dr. L. Genton for her language assistance.

\section{References}

Abdallah BM, Kassem M (2009) The use of mesenchymal (skeletal) stem cells for treatment of degenerative diseases: current status and future perspectives. J Cell Physiol 218:9-12

Adamovic T, Trossö F, Roshani L et al (2005) Oncogene amplification in the proximal part of chromosome 6 in rat endometrial adenocarcinoma as revealed by combined BAC/PAC FISH, chromosome painting, zoo-FISH, and allelotyping. Genes Chromosomes Cancer 44:139-153

Aguilar S, Nye E, Chan J et al (2007) Murine but not human mesenchymal stem cells generate osteosarcoma-like lesions in the lung. Stem Cells 25:1586-1594

Bernardo ME, Zaffaroni N, Novara F et al (2007) Human bone marrow-derived mesenchymal stem cells do not undergo transformation after long-term in vitro culture and do not exhibit telomere maintenance mechanisms. Cancer Res 67:9142-9149

Brodeur GM, Seeger RC, Schwab M, Varmus HE, Bishop JM (1984) Amplification of N-myc in untreated human neuroblastomas correlates with advanced disease stage. Science 224:1121-1124

Brooke G, Cook M, Blair C et al (2007) Therapeutic applications of mesenchymal stromal cells. Semin Cell Dev Biol 18:846-858

Caplan AI (2007) Adult mesenchymal stem cells for tissue engineering versus regenerative medicine. J Cell Physiol 213:341-347

Committee for a Standardized Karyotype of Rattus Norvegicus (1973) Standard karyotype of the Norway rat, Rattus norvegicus. Cytogenet Cell Genet 12:199-205

Doerr HW, Cinatl J, Stürmer M, Rabenau HF (2003) Prions and orthopedic surgery. Infection 31:163-171

Dominici M, Le Blanc K, Mueller I et al (2006) Minimal criteria for defining multipotent mesenchymal stromal cells. The International Society for Cellular Therapy position statement. Cytotherapy 8:315-317

Donzelli E, Salvadè A, Mimo P et al (2007) Mesenchymal stem cells cultured on a collagen scaffold: in vitro osteogenic differentiation. Arch Oral Biol 52:64-73

Furlani D, Li W, Pittermann E et al (2009) A transformed cell population derived from cultured mesenchymal stem cells has no functional effect after transplantation into the injured heart. Cell Transplant 18:319-331

Goffredo D, Conti L, Di Febo F et al (2008) Setting the conditions for efficient, robust and reproducible generation of functionally active neurons from adult subventricular zone-derived neural stem cell. Cell Death Diff 15 (12):1847-1856

Guryev V, Saar K, Adamovic T et al (2008) Distribution and functional impact of DNA copy number variation in the rat. Nat Genet 40:538-545

Izadpanah R, Kaushal D, Kriedt C et al (2008) Long-term in vitro expansion alters the biology of adult mesenchymal stem cells. Cancer Res 68:4229-4238

Lee KD, Kuo TK, Whang-Peng J et al (2004) In vitro hepatic differentiation of human mesenchymal stem cells. Hepatology 40:1275-1284

Liebman J, Goldberg RL (2001) Chondrocyte culture and assay. Curr Protoc Pharmacol 12:12.2.1-12.2.18

Mannello F, Tonti GA (2007) Concise review: no breakthroughs for human mesenchymal and embryonic stem cell culture: conditioned medium, feeder layer, or feeder-free; medium with fetal calf serum, human serum, or enriched plasma; serum-free, serum replacement nonconditioned medium, or ad hoc formula? All that glitters is not gold! Stem Cells 25:1603-1609

Meuleman N, Tondreau T, Delforge A et al (2006) Human marrow mesenchymal stem cell culture: serum-free medium allows better expansion than classical alpha-MEM medium. Eur J Haematol 76:309-316

Meza-Zepeda LA, Noer A, Dahl JA, Micci F, Myklebost O, Collas P (2008) High-resolution analysis of genetic stability of human adipose tissue stem cells cultured to senescence. J Cell Mol Med 12:553-563

Miura M, Miura Y, Padilla-Nash HM et al (2006) Accumulated chromosomal instability in murine bone marrow mesenchymal stem cells leads to malignant transformation. Stem Cells 24:1095-1103

Neuhuber B, Swanger SA, Howard L, Mackay A, Fischer I (2008) Effects of plating density and culture time on bone marrow stromal cell characteristics. Exp Hematol 36:1176-1185

Pal R, Hanwate M, Jan M, Totey S (2009) Phenotypic and functional comparison of optimum culture conditions for upscaling of bone marrow-derived mesenchymal stem cells. J Tissue Eng Regen Med 3:163-174

Røsland GV, Svendsen A, Torsvik A et al (2009) Long-term cultures of bone marrow-derived human mesenchymal stem cells frequently undergo spontaneous malignant transformation. Cancer Res 69:5331-5339

Rubie H, Hartmann O, Michon J et al (1997) N-Myc gene amplification is a major prognostic factor in localized neuroblastoma: results of the French NBL 90 study. Neuroblastoma Study Group of the Société Francaise d'Oncologie Pédiatrique. J Clin Oncol 15:1171-1182

Rubio D, Garcia-Castro J, Martín MC et al (2005) Spontaneous human adult stem cell transformation. Cancer Res 65:3035-3039

Shahdadfar A, Frønsdal K, Haug T, Reinholt FP, Brinchmann JE (2005) In vitro expansion of human mesenchymal stem cells: choice of serum is a determinant of cell proliferation, 
differentiation, gene expression, and transcriptome stability. Stem Cells 23:1357-1366

Shakhova O, Leung C, van Montfort E, Berns A, Marino S (2006) Lack of Rb and p53 delays cerebellar development and predisposes to large cell anaplastic medulloblastoma through amplification of N-Myc and Ptch2. Cancer Res 66:5190-5200

Sotiropoulou PA, Perez SA, Salagianni M, Baxevanis CN, Papamichail M (2006) Cell culture medium composition and translational adult bone marrow-derived stem cell research. Stem Cells 24:1409-1410

Spiliotopoulos D, Goffredo D, Conti L et al (2009) An optimized experimental strategy for efficient conversion of embryonic stem (ES)-derived mouse neural stem (NS) cells into a nearly homogeneous mature neuronal population. Neurobiol Dis 34 (2):320-331

Tolar J, Nauta AJ, Osborn MJ et al (2007) Sarcoma derived from cultured mesenchymal stem cells. Stem Cells 25:371-379

Tondreau T, Dejeneffe M, Meuleman N et al (2008) Gene expression pattern of functional neuronal cells derived from human bone marrow mesenchymal stromal cells. BMC Genomics 9:166
Tonti GA, Mannello F (2008) From bone marrow to therapeutic applications: different behaviour and genetic/epigenetic stability during mesenchymal stem cell expansion in autologous and foetal bovine sera? Int $\mathrm{J}$ Dev Biol 52:1023-1032

Wang Y, Huso DL, Harrington J et al (2005) Outgrowth of a transformed cell population derived from normal human BM mesenchymal stem cell culture. Cytotherapy 7:509519

Wexler SA, Donaldson C, Denning-Kendall P, Rice C, Bradley B, Hows JM (2003) Adult bone marrow is a rich source of human mesenchymal 'stem' cells but umbilical cord and mobilized adult blood are not. $\mathrm{Br} \mathrm{J}$ Haematol 121:368-374

Yu D, Silva GA (2008) Stem cell sources and therapeutic approaches for central nervous system and neural retinal disorders. Neurosurg Focus 24(3-4):E11

Zhang ZX, Guan LX, Zhang K et al (2007) Cytogenetic analysis of human bone marrow-derived mesenchymal stem cells passaged in vitro. Cell Biol Int 31:645-648

Zhou YF, Bosch-Marce M, Okuyama H et al (2006) Spontaneous transformation of cultured mouse bone marrow-derived stromal cells. Cancer Res 66:10849-10854 